\title{
BETWEEN-YEAR BREEDING DISPERSAL IN RED-COCKADED WOODPECKERS: MULTIPLE CAUSES AND ESTIMATED COST
}

\author{
Susan J. Daniels ${ }^{1}$ And JefFrey R. Walters \\ ${ }^{1}$ Department of Biology, Virginia Polytechnic Institute and State University, Blacksburg, Virginia 24061 USA
}

\begin{abstract}
We studied between-year dispersal of adult females within a population of cooperatively breeding Red-cockaded Woodpeckers (Picoides borealis) in the Sandhills of North Carolina, using data collected between 1980 and 1995. We tested four hypotheses about the cause of breeding dispersal: inbreeding avoidance, mate choice, site choice, and social constraints. In addition, we assessed relationships among age, reproductive failure, and breeding dispersal, and we estimated cost of breeding dispersal by plotting mortality against dispersal rate as a function of circumstance.

Breeding dispersal in the population that we studied is associated with multiple factors. Inbreeding avoidance influences dispersal of females whose sons inherit their natal territories. Mate choice influences dispersal of females whose mates have died; these females acquire older, higher quality mates by dispersing. In this study, there was no clear relationship between site choice and breeding dispersal. Social constraints do not appear to affect breeding dispersal in this population: no evidence was found to suggest that dispersal is associated with female-female competition, within-group competition for resources, or reproductive competition between mothers and helper sons.

The effect of reproductive failure on breeding dispersal changes with female age. Reproductive failure is associated with breeding dispersal in young females only (those $<3$ yr old). Estimated mortality rates for breeding females that attempt to disperse vs. those that do not attempt to disperse were $59 \%$ and $26 \%$, respectively; the difference between those rates is the estimated cost of breeding dispersal in this population, an additional $33 \%$ probability of mortality. Thus, breeding females more than double their risk of mortality by dispersing.
\end{abstract}

Key words: $\quad$ breeding dispersal; cooperative breeding; cost of dispersal; inbreeding avoidance; mate choice; North Carolina; Picoides borealis; Red-cockaded Woodpecker; site choice; social constraints.

\section{INTRODUCTION}

Dispersal of breeding adults affects population genetics and population dynamics by providing gene flow, reducing inbreeding, and increasing reproduction (Greenwood and Harvey 1982). We examine $>240$ between-year movements of breeding females within a population of Red-cockaded Woodpeckers (Picoides borealis) to test four hypothesized causes of those movements: inbreeding avoidance, mate choice, site choice, and social constraints. We assess relationships among age, reproductive failure, and breeding dispersal, and we estimate cost of breeding dispersal through a comparison of mortality and dispersal rates within circumstance.

Birds in different circumstances may disperse for different reasons. Recognizing that, we first partition dispersal events by three broad circumstances: death of a mate, reproductive failure, and no mate death or failure. We then test the following predictions of hypotheses about the cause of breeding dispersal, both

Manuscript received 21 September 1998; revised 1 June 1999; accepted 6 August 1999; final version received 14 September 1999.

${ }^{1}$ E-mail: sdaniels@vt.edu separately and simultaneously. Multiple simultaneous effects indicate multiple causes of breeding dispersal (Hilborn and Mangel 1997).

\section{Inbreeding avoidance}

Inbreeding avoidance occurs when breeding birds disperse to avoid costs of close inbreeding. The hypothesis applies only to females dispersing after death of their mates. For females in that circumstance, inbreeding avoidance predicts that frequency of dispersal increases when sons inherit breeding status on the female's territory (Table 1, prediction 1a). The prediction is unique to the inbreeding avoidance hypothesis.

\section{Mate choice}

The mate choice hypothesis is that breeding birds disperse to improve the quality of their mates. We measure quality by age of the male, but set the maximum value at three years, because male reproductive success increases with age until age three, but is constant thereafter (Walters 1990). Success of males $\geq 10 \mathrm{yr}$ old is probably reduced, but there are relatively few of those males in the population (J. R. Walters, unpublished data).

For females dispersing after the death of their mates, 
TABle 1. Predictions of four hypotheses for the dispersal of breeding female Red-cockaded Woodpeckers.

\begin{tabular}{|c|c|c|}
\hline Hypothesis & Prediction & Results $\dagger$ \\
\hline 1. Inbreeding avoidance & 1a: Females disperse more frequently if sons attain breeding status. & **** \\
\hline \multicolumn{3}{|l|}{ 2. Mate choice } \\
\hline \multirow[t]{2}{*}{ i. Females whose mates die } & 2a: New mates are of higher quality than replacement males. & $* * *$ \\
\hline & $\begin{array}{l}\text { 2b: Females disperse more frequently if replacement males are of low } \\
\text { quality. }\end{array}$ & $* * *$ \\
\hline \multirow[t]{4}{*}{ ii. Females whose mates survive } & 2c: New mates are of higher quality than mates left behind. & NS \\
\hline & $\begin{array}{l}\text { 2d: Females disperse more frequently if their mates are of low quali- } \\
\text { ty. }\end{array}$ & ** \\
\hline & 2e: Females disperse more frequently after reproductive failure. & $* * *$ \\
\hline & 2f: Females disperse more frequently after poor reproduction. & NS \\
\hline \multirow[t]{4}{*}{ 3. Site choice } & $\begin{array}{l}\text { 3a: For dispersing females, new sites are of higher quality than old } \\
\text { sites. }\end{array}$ & NS \\
\hline & 3b: Females disperse less frequently if helpers are present. & *** \\
\hline & 3c: Females disperse more frequently after reproductive failure. & $* * *$ \\
\hline & 3d: Females disperse more frequently after poor reproduction. & NS \\
\hline \multicolumn{3}{|l|}{ 4. Social constraints } \\
\hline i. Female-female competition & 4a: Replacement females are older than dispersing females. & NS \\
\hline $\begin{array}{l}\text { ii. Within-group competition for re- } \\
\text { sources }\end{array}$ & 4b: Females disperse more frequently if helpers are present. & NS \\
\hline $\begin{array}{l}\text { iii. Within-group reproductive com- } \\
\text { petition }\end{array}$ & 4c: Females disperse more frequently if helper sons are present. & NS \\
\hline
\end{tabular}

Note: Boldface type in the second column indicates predictions unique to that hypothesis.

$\dagger$ Significance levels of evidence for the prediction: $* * P<0.01$; *** $P<0.001$; NS, nonsignificant.

the mate choice hypothesis predicts that quality of new mates on territories to which females disperse is higher than that of replacement males (males replacing dead mates) on the original territories (Table 1, prediction 2a). It also predicts that frequency of dispersal increases if replacement males are of low quality (2b). For females dispersing while their mates survive, mate choice predicts that quality of new mates is higher than that of old mates (2c), and that dispersal increases if mates are of low quality $(2 \mathrm{~d})$. Those four predictions are unique to the mate choice hypothesis.

Other predictions of the mate choice hypothesis are that females whose mates survive will disperse more frequently after reproductive failure (2e) and poor reproduction (2f). Those two predictions are shared by the site choice hypothesis.

\section{Site choice}

Site choice refers to breeding birds that disperse to obtain a higher quality site. The hypothesis uniquely predicts that the quality of new territories is higher than that of original territories (prediction 3a), and that frequency of dispersal decreases with presence of helpers (3b), because helpers are an indicator of high territory quality. In addition, site choice has two predictions in common with mate choice: frequency of dispersal increases with reproductive failure $(3 \mathrm{c})$ and poor reproduction (3d).

\section{Social constraints}

The social constraints hypothesis refers to breeding birds that disperse in response to intraspecific interactions (i.e., dispersal is a consequence of social be- havior; Payne and Payne 1993). We identified three possible interactions in Red-cockaded Woodpeckers: female-female competition, within-group competition for resources, and within-group reproductive competition between mothers and helper sons. Female-female competition predicts that new females in original sites (replacement females) are older than dispersing females (4a), based on the assumption that older females are dominant. Within-group competition for resources predicts that females disperse more frequently as group size increases and one or more helpers are present on the original territory (4b). Within-group reproductive competition predicts that females disperse more frequently if helper sons are present in the group (4c; Gowaty and Lennartz 1985). Those predictions are unique to the social constraints hypothesis.

\section{Methods}

Study species, study area, and data collection

The Red-cockaded Woodpecker is an endangered, cooperatively breeding species endemic to the pine savannas of the southeastern United States. Fledgling males may either disperse or delay dispersal and remain on their natal territories as helpers, whereas almost all fledgling females disperse (Walters et al. 1988). Helpers may eventually become breeders by inheriting breeding status on the natal territory or by dispersing to a neighboring one (Walters et al. 1988). Red-cockaded Woodpeckers live on permanent territories, in groups consisting of a solitary male, a breeding pair, or a breeding pair with one or more helpers (Lennartz et al. 1987, Walters et al. 1988). Movement of females, both young and adult, is an important factor determin- 
ing the number of breeding groups, and the number of breeding groups is, in turn, a critical determinant of population behavior in this species (Walters 1991).

The study area encompasses $>110000$ ha of secondgrowth longleaf pine (Pinus palustris) savanna in the Sandhills of south-central North Carolina, and contains $>500$ individuals in $\sim 220$ groups, representing the western half of the Sandhills population. Data used in this study were collected between 1980 and 1995; between 1982 and 1995, all known groups within the study area were monitored. Individuals were banded with a unique combination of color bands, and reproduction of groups was monitored each breeding season. Most birds were banded as nestlings, and each breeding season, all members of each group were identified. Location and status of most individuals in the study area were determined each year. Walters et al. (1988) give further information about the study population and methods of data collection, and Carter et al. (1983) give a detailed description of the habitats within the study area.

\section{Definitions}

Breeding dispersal.-We defined breeding dispersal as movement between consecutive breeding opportunities. Each female had one breeding opportunity per year if she was $\geq 1 \mathrm{yr}$ old and was the only or oldest female residing within a group; in this species, females do not occupy territories that have no male present, and do not breed in different locations in the same season. This definition of breeding dispersal includes movements between breeding sites (Greenwood 1980), movements between consecutive breeding attempts (Part and Gustafsson 1989, Montalvo and Potti 1992), and movements of adults that were in breeding positions but did not attempt to nest (i.e., did not lay eggs). The percentage of pairs that did not attempt to nest varied annually from $4 \%$ to $25 \%$.

Reproductive failure.-We defined reproductive failure as either failure to attempt to nest (no nest attempt) or failure to produce at least one fledgling from a clutch (nest failure). We combined those two types of failures for most analyses to maintain sample size. Because frequencies of dispersal after each circumstance were similar (13.4\% of females experiencing nest failure and $17 \%$ of females without a nest attempt dispersed between breeding seasons), we felt that this step was appropriate; however, we recognized the distinction between them in one set of analyses and in the Discussion.

Territory quality.-We measured territory quality using natality and mortality rates for each territory (following Ligon and Ligon 1990). A good territory produces high numbers of young and enables high survivorship of adults. Therefore, we divided average annual production (total fledglings produced on the territory divided by the number of years that territory has been monitored) by average annual adult mortality (the number of adults presumed to have died on the territory divided by total number of adult bird-years).

\section{Samples}

In most years, there were $\sim 180-210$ breeding females in the study area. We pooled observations for 984 individuals in 317 territories across 15 years (1980-1994), for a total of 2698 female bird-years. (Territories not containing a breeding female were either unoccupied or occupied by a solitary male.) We used female bird-years rather than one randomly chosen observation per female in order to retain as much information as possible, because each female in each year faced different circumstances.

\section{Statistical analyses}

The majority of analyses were chi-square tests on frequencies with which breeding females in specific circumstances disperse. Fisher's exact test was used in two cases in which expected frequencies were insufficient for a chi-square test. For other analyses, parametric procedures were employed whenever distributions were not significantly different from normal (Shapiro-Wilks test, $P \leq 0.10$ ), and distribution-free median procedures were used when data were not symmetrically distributed. Overall significance level $(\alpha)$ was set at $P \leq 0.05$ for all tests or sets of multiple tests other than those of normality.

For groups of multiple tests, we used the sequential Bonferroni technique to assess significance of individual tests (Holm 1979, Rice 1989, Chandler 1995). Individual tests were deemed significant if individual $P$ values $\left(P_{i}\right)$, ordered from smallest the largest, were less than a sequentially increasing significance level $(\alpha /(1$ $+k-i$ ), for $k$ tests). For significant individual tests, we report both the individual $P$ value and the adjusted significance level against which it was compared. For insignificant tests, we report only the $P$ value, because the procedure requires that comparisons cease after the first insignificant result; therefore, further adjusted significance levels were not calculated. There were three situations in which we grouped tests and applied the sequential Bonferroni adjustment: (1) similar predictions were tested for females in different circumstances, (2) the same test was performed on data with and without certain cases, or (3) correlations among more than two variables were assessed. Tests within the same group of multiple tests are not necessarily reported together.

Test for simultaneous effects.-To assess the significance of effects simultaneously, we performed a logistic regression. Our dependent variable was whether or not the female dispersed between year $x$ and year $x$ +1 , and only females that survived were included. Independent variables were: age of female (year $x$ ), death of her mate (between year $x$ and year $x+1$ ), reproductive failure (year $x$ ), age of mate (year $x$ ), difference in male age (year $x+1$ ), maternity of male 


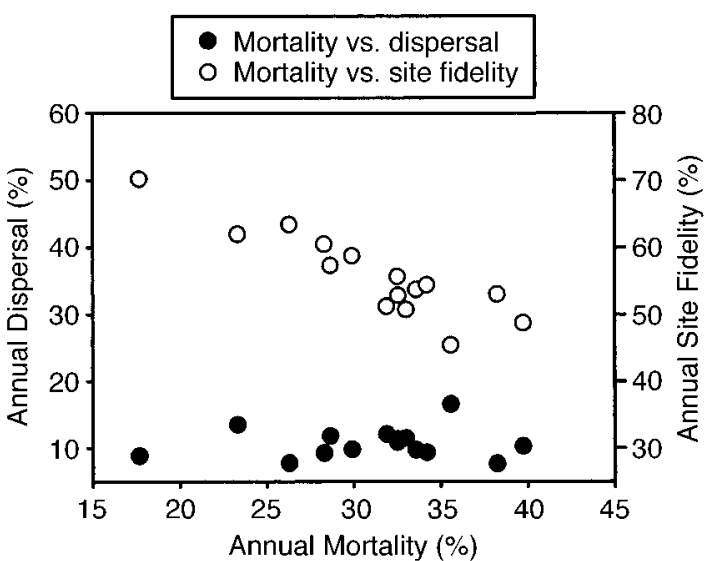

FIG. 1. Annual rates of dispersal and site fidelity plotted against mortality for adult female Red-cockaded Woodpeckers in the North Carolina Sandhills (1980-1994; $n=2658$ bird-years). Annual dispersal was independent of mortality, whereas annual mortality and site fidelity were highly, inversely correlated.

(year $x+1$ ), number of helpers (year $x$ ), number of fledglings produced (year $x$ ), territory quality (year $x$ ), and difference in territory quality (year $x+1$ ). Mate death and reproductive failure were binary variables for which yes equaled 1 and no equaled 0 . Age of female, age of mate, and difference in male age included birds whose ages were known as a minimum (e.g., after their second year) as well as those whose ages were known exactly (e.g., second year) to increase sample size. Difference in male age was calculated as age of the new mate minus age of the replacement male; for females that did not disperse, this variable equaled 0 . Difference in territory quality was calculated as quality of the new territory minus that of the original territory; for females that did not disperse, this variable equaled 0 . Maternity of the male refers to the breeding male in the original territory in year $x+1$, whether or not the female dispersed; this was a binary variable that equaled 1 if the male was a son and 0 if he was not a son of the female in question. Number of fledglings produced had four possible values: $0,1,2, \geq 3$. To retain sample size, age of replacement females was not included in the logistic regression.

\section{RESUlts}

Annual rates of dispersal, site fidelity, and mortality

Each year, $12.1 \pm 0.7 \%$ of breeding females (mean $\pm 1 \mathrm{SE}$ ) dispersed to another location, $55.8 \pm 1.6 \%$ of breeding females remained on territory, and $31.1 \pm$ $1.5 \%$ of breeding females died. An estimated $6.5 \%$ of breeding females presumed dead may instead have dispersed off the study site (Walters et al. 1988). In addition, $1.0 \% \pm 0.2 \%$ of breeding females became floaters. Walters et al. (1988) reported similar rates for this population for the years 1980-1985.

Annual dispersal rate was not correlated with annual rates of site fidelity or mortality, but site fidelity and mortality were highly, inversely correlated (Fig. 1; Spearman rank correlations with adjusted $\alpha$; for fidelity and mortality, $n=15, r=-0.85, P=0.0001, \alpha=$ 0.0167; for dispersal and fidelity, $n=15, r=-0.43$, $P=0.11$; for dispersal and mortality, $n=15, r=$ $-0.02, P=0.94)$. Dispersal was also much less variable than were mortality and site fidelity (Fig. 1). Because annual dispersal was not correlated with annual mortality, we conclude that breeding dispersal is not influenced by the number of breeding vacancies in the population.

\section{Frequencies of dispersal by circumstance}

Of the dispersing females, 65\% (158 of 242) moved after mate death, 38\% (91 of 242) moved after reproductive failure, and 17\% (42 of 242) moved after no mate death or failure. Mate death and reproductive failure were not mutually exclusive categories; $20 \%$ (49 of 242) of dispersing females moved after both reproductive failure and mate death. Frequencies with which females dispersed and remained on territory within each of these circumstances are presented in Table 2. Both reproductive failure and mate death were significantly associated with breeding dispersal (Table 2).

\section{Test of inbreeding avoidance}

The hypothesis of inbreeding avoidance was tested by comparing the number of times a breeding female's son inherited the breeding male position with the frequency with which the female dispersed. Females dispersed significantly more often if replacement males were sons than if they were not sons (chi-square test,

TABLE 2. Frequencies of dispersal and site fidelity of breeding female Red-cockaded Woodpeckers by two exclusive circumstances: mate death only and reproductive failure only.

\begin{tabular}{lcccc}
\hline \hline \multicolumn{1}{c}{ Circumstance } & $\begin{array}{c}\text { Female } \\
\text { dispersed }\end{array}$ & $\begin{array}{c}\text { Female } \\
\text { remained }\end{array}$ & $\chi^{2}$ & $P \dagger$ \\
\hline Mate death only & $109(29)$ & $121(201)$ & 313.7 & 0.001 \\
No mate death or failure & $42(122)$ & $929(849)$ & & 0.001 \\
Reproductive failure only & $42(23)$ & $317(336)$ & 24.1 & \\
No mate death or failure & $42(61)$ & $929(910)$ & & \\
\hline
\end{tabular}

Note: Expected values are given in parentheses.

$\dagger$ Chi-square tests, df $=1$. 

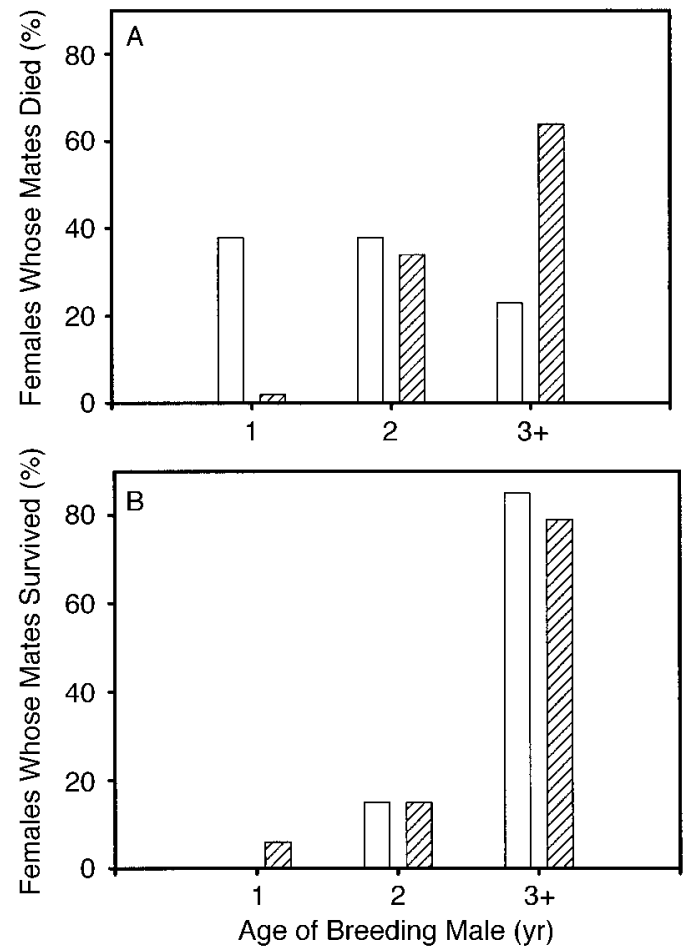

FIG. 2. Quality of males on territories to and from which breeding female Red-cockaded Woodpeckers dispersed. Quality was measured by three age categories, in the year following dispersal (year $x+1$ ). For dispersing females whose mates had died (A), ages of new mates (hatched bars) were greater than those of males replacing dead mates on original territories (open bars), suggesting an influence of mate choice on breeding dispersal. For dispersing females whose mates survived (B), ages of new mates (hatched bars) were similar to those of original mates (open bars), suggesting a cause of these movements apart from mate choice.

$n=221, \chi^{2}=61.3$, df $\left.=1, P=0.001\right)$. In fact, in $>90 \%$ of cases ( 49 of 53 ) in which the son became the breeding male, the breeding female dispersed. This prediction unique to inbreeding avoidance (1a) was confirmed.

Because that association was so strong, the 53 cases in which a son became the breeding male were omitted from all further analyses except the estimate of dispersal cost. Mate death was still highly associated with the movement of breeding females (chi-square test with adjusted $\alpha, n=1281, \chi^{2}=247$, df $=1, P=0.001$, $\alpha=0.05)$ after those cases were removed.

\section{Tests of mate choice}

Dispersal after death of a mate.-In 83\% (235 of 282) of cases in which the breeding female survived but her mate died, and no son inherited the territory, a replacement male occupied the breeding position. In the remaining cases, the territory became abandoned.

Dispersal of females whose mates died was associated with the quality of replacement males, being more frequent when replacement males were young (chi- square test with adjusted $\alpha, n=195, \chi^{2}=20.8, \mathrm{df}=$ $2, P=0.001, \alpha=0.025)$. For dispersing females, new mates on the subsequent territories were of significantly higher quality than replacement mates on original territories (Fig. 2A gives population distributions; pairedsign test on difference in male quality for each female, with adjusted: $\alpha: n=47, M=14, P=0.0001, \alpha=$ $0.025)$. These two predictions unique to mate choice (2a, 2b) were confirmed.

Dispersal without death of a mate.-Females whose mates survived were more likely to disperse if their mates were young, low-quality males (chi-square test with adjusted $\alpha, n=819, \chi^{2}=13.8, \mathrm{df}=2, P=0.001$, $\alpha=0.05)$. However, ages of original and new mates were not significantly different (Fig. 2B gives population distributions; paired-sign test on difference in quality for each female: $n=34, M=-1, P=0.73$ ). By definition, the original mate surviving to the year following dispersal was $\geq 2 \mathrm{yr}$ old, and new mates were largely $\geq 2$ yr old (Fig. 2B). Of those two predictions unique to the mate choice hypothesis $(2 \mathrm{c}, 2 \mathrm{~d})$, only one (2c) was supported.

Whether the female stayed or dispersed was significantly associated with reproductive failure (Table 2), but not with the number of fledglings produced from successful nests (chi-square test on 1,2 , and $\geq 3$ fledglings, $n=948, \chi^{2}=2.5$, df $=2, P=0.28$ ). Of those two predictions common to both mate choice and site choice hypotheses (2e, 2f), only one (2e) was supported.

The association between reproductive failure and breeding dispersal supports the mate choice hypothesis only if reproductive failure can be attributed to lowquality males. Although causes of each failure were not documented, reproductive failure was associated with male age in two ways: young males failed to nest more often than older males, and young males suffered increased nest failures (Fig. 3; chi-square tests with adjusted: age of breeding male $[1,2, \geq 3 \mathrm{yr}]$ vs. nest

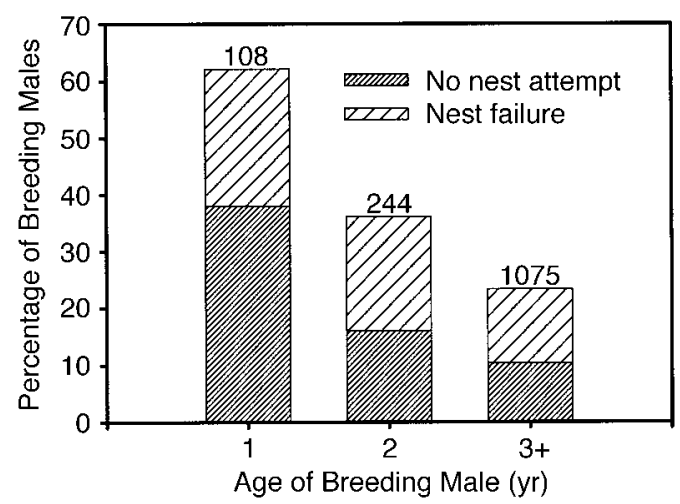

FIG. 3. Relationship between age of breeding male Redcockaded Woodpeckers and rates of nest failure (finely hatched bars) and no nest attempt (coarsely hatched bars). Both types of reproductive failures decrease with increasing age of the male. 
attempt, $n=1427, \chi^{2}=66.4, \mathrm{df}=2, P=0.001, \alpha$ $=0.025$; age of breeding male vs. nest failure, $n=$ $1236, \chi^{2}=33.0$, df $\left.=2, P=0.001, \alpha=0.05\right)$. Frequencies of each type of failure were roughly equal for dispersing females: of 42 females dispersing after reproductive failure but no mate death, 20 suffered nest failure and 22 had not attempted to nest. Fertility of males was not assessed in this study.

\section{Tests of site choice}

Territory quality, as measured by our quality index (see Methods), was not significantly different between new and old territories for females dispersing after reproductive failure only (paired $t$ test on the difference between territories, with adjusted $\alpha: n=42, t=-0.69$, $P=0.49)$, females dispersing after mate death $(n=$ $108, t=-1.45, P=0.59$ ), or females dispersing after no mate death or reproductive failure ( $n=42, t=0.67$, $P=0.51$ ). Prediction $3 \mathrm{a}$, unique to the site choice hypothesis, was not confirmed.

Presence of helpers on the original territory, a sign of high territory quality, did not affect dispersal of females whose mates died (excluding sons inheriting, chi-square test with adjusted $\alpha, n=282$, df $=1, \chi^{2}=$ $1.7, P=0.19)$. However, dispersal of females whose mates survived was significantly less likely if helpers were present (excluding reproductive failures, chisquare test with adjusted $\alpha, n=971$, df $=1, \chi^{2}=$ 11.9, $P=0.001, \alpha=0.025)$. Thus, that prediction unique to site choice ( $3 b$ ) was supported for those females whose mates survived, but not for those whose mates died.

Reproductive failure, regardless of mate death, was significantly associated with dispersal (prediction $3 \mathrm{c}$ is confirmed; Fig. 2 and tests described previously), which supports the site quality hypothesis to whatever extent reproductive failure was influenced by site quality. Unfortunately, the relationship between site quality and reproductive failure was not assessed in this study. A low number of fledglings from successful nests was not associated with female dispersal (prediction $3 \mathrm{~d}$ is not supported).

\section{Tests of social constraints}

Female-female competition.-To test for female-female competition, we compared ages of dispersing females with those of females replacing them. However, $\sim 40 \%$ (64 of 158, including sons inheriting) of females dispersing after mate death were not replaced; of 64 such cases, 34 sites became abandoned and 30 sites contained a new, solitary male. About $20 \%$ (17 of 84) of females dispersing while their mates survived were not replaced; their former mates became solitary males.

Dispersing females were older than their replacements by an average of $1.45 \pm 0.22 \mathrm{yr}$ and a median of $1 \mathrm{yr}$; that difference was significantly greater than zero (paired-sign test, $n=65, M=23, P=0.0001$; see Fig. 4 for population distributions). Replacement

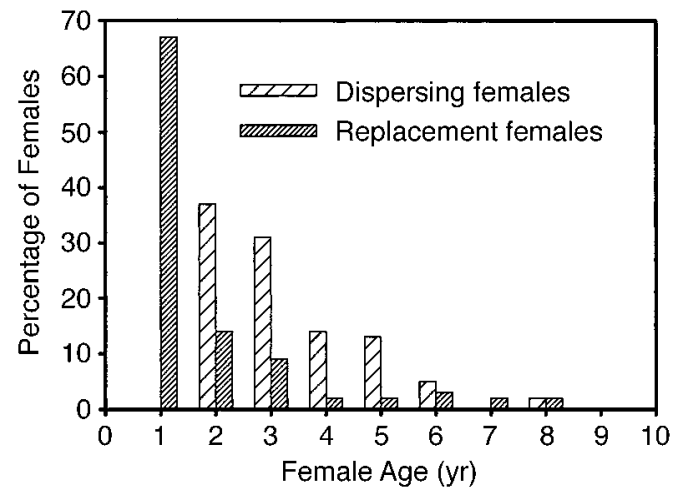

FIG. 4. Age distributions of dispersing female Red-cockaded Woodpeckers (coarsely hatched bars) and females occupying the vacated breeding position (replacement females; finely hatched bars). Dispersing females are older than replacement females, suggesting no effect of social constraints on breeding dispersal.

females were older than dispersing females in only 7 of 65 cases. Thus, female-female competition was not supported.

Within-group competition for resources.-Although the presence of helpers may increase within-group competition, it was not associated with breeding dispersal after mate death and was negatively associated with dispersal while the mate remains on territory. Prediction $4 \mathrm{~b}$ is not supported; there was no evidence that within-group competition influenced breeding dispersal.

Within-group reproductive competition.-Reproductive competition predicts that females will disperse more often if helper sons are present on the original territory (4c). To exclude the effect of sons inheriting, we considered only cases in which the breeding male survived and helpers were present. Females in those circumstances very rarely dispersed, and relatedness of helpers was not associated with an increase in dispersal (Fisher's exact test, $n=403, P=1.00$ ). Reproductive competition was not found to influence breeding dispersal of female Red-cockaded Woodpeckers.

\section{Age of breeding female}

Dispersing females were significantly younger than site-faithful females for all circumstances combined (median one-way analysis, $\chi^{2}=9.3, \mathrm{df}=1, P=0.002$ ). For females experiencing mate death, those dispersing were equal in age to those remaining $\left(\chi^{2}=1.5\right.$, df $=$ $1, P=0.22)$. For females experiencing reproductive failure, those dispersing were significantly younger than those remaining $\left(\chi^{2}=8.2, \mathrm{df}=1, P=0.004\right)$. For females experiencing neither mate death or failure, those dispersing were also significantly younger than those remaining, although sample size for this last category was low $\left(\chi^{2}=6.1\right.$, df $\left.=1, P=0.01\right)$.

Among dispersing females, females moving after reproductive failure were significantly younger than fe- 


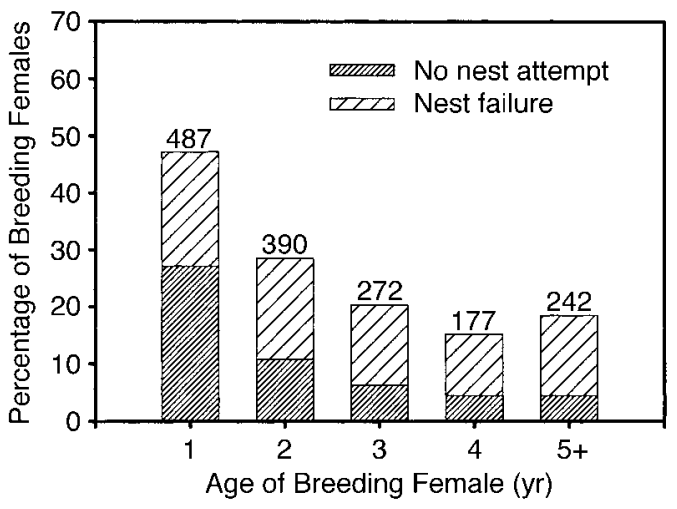

FIG. 5. Relationship between age of breeding female Redcockaded Woodpeckers and rates of nest failure (finely hatched bars) and no nest attempt (coarsely hatched bars). Both types of reproductive failures decrease with increasing age of the female.

males moving after death of their mates, and females moving after no mate death or reproductive failure (mean age $=1.44 \pm 0.13,2.64 \pm 0.31$, and $2.24 \pm$ $0.25 \mathrm{yr}$, respectively; median age $=1,2$, and $2 \mathrm{yr}$, respectively; median one-way analysis, $\chi^{2}=11.5$, df $=2, P=0.003$ ). Young, inexperienced females were more susceptible to reproductive failure; frequencies of both nest failure and no nest attempt were strongly associated with age, being highest for 1-yr-old females (Fig. 5; chi-square tests with adjusted $\alpha$ : age of breeding female [ages $\geq 5 \mathrm{yr}$ pooled to maintain cell sample size] vs. nest attempt, $n=1568, \chi^{2}=121.6$, df $=4$, $P=0.001, \alpha=0.025$; age of breeding female vs. nest failure, $n=1358, \chi^{2}=29.3, \mathrm{df}=4, P=0.001, \alpha=$ $0.05)$.

To detect whether reproductive failure was associated with dispersal among older females, we repeated the analysis presented in the first Results section, but excluded all young females. Reproductive failure (without mate death) was still significantly associated with dispersal when 1-yr-olds were excluded $\left(\chi^{2}=6.1\right.$, df $=1, P=0.013, \alpha=0.025)$. When both 1 - and 2yr-olds were excluded, however, reproductive failure was not significantly associated with dispersal (Fisher's exact test, $n=344, P=0.22$ ). Therefore, effect of reproductive failure on dispersal changed with age: reproductive failure was significantly associated with dispersal of young females, but not with dispersal of females $\geq 3$ yr old.

\section{Multiple causes of breeding dispersal}

The dispersal of breeding females was affected by multiple simultaneous factors: mate death, difference in male age in year $x+1$, maternity of breeding male in year $x+1$, number of helpers, reproductive failure, and the interaction of female age and reproductive failure (Table 3). Results of logistic regression support those of individual tests, and simultaneous significance suggests multiple causes: inbreeding avoidance, supported by the effect of male maternity, and mate choice, supported by the effect of the difference in male age. Site choice was suggested by the negative effect of the number of helpers, which was clarified by removing the cases in which sons inherited the breeding position (Table 3B).

One minor difference exists between results of separate tests and logistic regression. Analyzed separately, age of mate was associated with dispersal of breeding females whose mates survived, whereas in logistic regression, age of mate in year $x$ was not significant (Table 3). It may be that the separate effect of age of mate (year $x$ ) is better explained by reproductive failure in simultaneous testing. Such an interpretation is consistent with the strong influence of reproductive failure even in the presence of the female age $\times$ reproductive failure interaction term. These results together suggest that it is reproductive failure associated with young males, rather than other attributes, that influences dispersal of females.

\section{Cost of breeding dispersal}

Across circumstances, mortality rates increased with increasing rates of breeding dispersal. We used that correlation to estimate mortality for females that do not disperse and for females that attempt to disperse, and thus estimated the cost of breeding dispersal. We plotted mortality rates for females within a specified set of circumstances against dispersal rates for females that survived, in the same set of circumstance (Fig. 6). Mortality of females that did not disperse is estimated by the left $y$-intercept (representing $0 \%$ dispersers): an estimated $26 \%$ of breeding females that do not disperse die. Mortality of females that attempted to disperse is estimated by the right $y$-intercept (representing 100\% dispersal of survivors): for a circumstance in which all females attempt to disperse, an estimated $59 \%$ of females die. Assuming the mortality rate of dispersing females is constant across circumstances, cost of breeding dispersal is then the difference between mortality rates for site-faithful females and dispersing females, or $33 \%$. Thus, females that attempt to disperse have a likelihood of mortality more than twice that of those that remain on territory.

\section{DisCUSSION}

Our results indicate that multiple factors are associated with female breeding dispersal in Red-cockaded Woodpeckers, including inbreeding avoidance, mate choice, and perhaps site choice. Dispersal of breeding females serves as an inbreeding avoidance mechanism, as a means to acquire a higher quality mate, and perhaps as a means to acquire a higher quality breeding site. Age of the breeding female is associated with dispersal through an interaction with reproductive failure, but we found no evidence that social constraints cause breeding dispersal. 
TABLE 3. Influence of multiple factors on between-year breeding dispersal of female Redcockaded Woodpeckers, shown by two logistic models of the likelihood that a breeding female dispersed.

\begin{tabular}{|c|c|c|c|}
\hline Source for model & Estimate & $\chi^{2}$ & $P$ \\
\hline \multicolumn{4}{|l|}{ Model A $\dagger$} \\
\hline $\begin{array}{l}\text { Difference in male age, new mate - replacement } \\
\text { male } \ddagger\end{array}$ & $0.72 \pm 0.12$ & 39.22 & 0.0001 \\
\hline Maternity of male & $3.95 \pm 0.63$ & 39.06 & 0.0001 \\
\hline Death of mate & $1.56 \pm 0.29$ & 29.67 & 0.0001 \\
\hline Reproductive failure & $1.70 \pm 0.63$ & 7.23 & 0.007 \\
\hline Number of helpers & $-0.56 \pm 0.27$ & 4.43 & 0.035 \\
\hline Age of female $\times$ nest failure & $-0.27 \pm 0.17$ & 2.54 & 0.10 \\
\hline Age of female & & 1.05 & 0.31 \\
\hline Number of fledglings produced $(0,1,2, \geq 3)$ & & 0.39 & 0.54 \\
\hline Territory quality, original site & & 0.39 & 0.54 \\
\hline Age of mate & & 0.23 & 0.63 \\
\hline Difference in territory quality, new - original§ & & 0.01 & 0.92 \\
\hline \multicolumn{4}{|l|}{ Model B\| } \\
\hline Death of mate & $1.59 \pm 0.22$ & 54.66 & 0.0001 \\
\hline $\begin{array}{l}\text { Difference in male age, new mate - replacement } \\
\text { male } \ddagger\end{array}$ & $0.50 \pm 0.08$ & 36.83 & 0.0001 \\
\hline Number of helpers & $-0.62 \pm 0.21$ & 8.71 & 0.003 \\
\hline Reproductive failure & $1.40 \pm 0.49$ & 8.11 & 0.004 \\
\hline Age of female $\times$ nest failure & $-0.32 \pm 0.16$ & 4.00 & 0.045 \\
\hline Age of female & & 0.64 & 0.42 \\
\hline Number of fledglings produced $(0,1,2, \geq 3)$ & & 0.61 & 0.43 \\
\hline Age of mate & & 0.42 & 0.52 \\
\hline Difference in territory quality, new - original§ & & 0.15 & 0.69 \\
\hline Territory quality, original site & & 0.09 & 0.76 \\
\hline
\end{tabular}

Notes: The first model (A; $n=130$ for moved, and $n=730$ for no move) includes the observations in which a female's son inherited the breeding male position and maternity of the breeding male (year $x+1)$ as a regressor. Those observations and that variable are excluded from the second model (B; $n=139$ for moved, and $n=1348$ for no move). Sample size increases for the second model because it includes cases in which maternity of the breeding male in year $x+1$ was uncertain. Parameter estimates $( \pm 1 \mathrm{SE}$ ) are given for important variables $(P<0.10)$ only.

$\dagger$ Model-fitting statistics: covariate $\chi^{2}=364.51, \mathrm{df}=11, P=0.0001$; percentage of concordant, discordant and tied pairs $=85.2 \%, 14.4 \%$, and $0.4 \%$, respectively.

$\ddagger$ For females that remained on territory, difference in male age $=0$.

$\S$ For females that remained on territory, difference in territory quality $=0$.

\| Model-fitting statistics: covariate $\chi^{2}=218.73, \mathrm{df}=10, P=0.0001$; percentage of concordant, discordant and tied pairs $=73.2 \%, 26.0 \%$, and $0.8 \%$, respectively.

Other studies also have shown multiple influences on breeding dispersal, although most have supported one hypothesis to the exclusion of others. Payne and Payne (1993), using data sets partitioned by sex, reported that female Indigo Buntings (Passerina cyanea) dispersed to find a better site, but males dispersed because of social constraints. Walters et al. (1988) suggested multiple causes of breeding dispersal in Redcockaded Woodpeckers: they clearly showed inbreeding avoidance, provided weak evidence for site choice, and suggested that both mate choice and social constraints may be important.

\section{Inbreeding avoidance}

Inbreeding avoidance is a common cause of breeding dispersal among cooperatively breeding birds (Walters et al. 1988). Close inbreeding (kinship coefficient $\geq 0.25$ ) is avoided in Acorn Woodpeckers (Melanerpes formicivorus; Koenig et al. 1984), Florida Scrub Jays (Aphelocoma coerulescens; Woolfenden and Fitzpatrick 1984), and Red-cockaded Wood- peckers (Walters et al. 1988). Walters et al. (1988), studying the same population of Red-cockaded Woodpeckers as in the present study, in the years 19801985, reported movement of breeding females in 14 of 15 cases in which a son attained breeding status in the female's territory. Here, we report movement in 45 of 49 such cases in the years 1980-1994. Close inbreeding results in a loss of fitness in this species (Daniels and Walters 2000). The fitness cost of close inbreeding and the high frequency of dispersal that serves to avoid close inbreeding indicate that movement of breeding females under these circumstances is an adaptive behavior.

Proximate mechanisms for inbreeding avoidance remain untested in this species. Kin recognition may be based on familiarity (i.e., association; Holmes and Sherman 1983). If in place, the mechanism must be fairly sophisticated: in 48 of 53 cases, breeding females did not disperse when a helper that was familiar, but not closely related, inherited the breeding male position. 


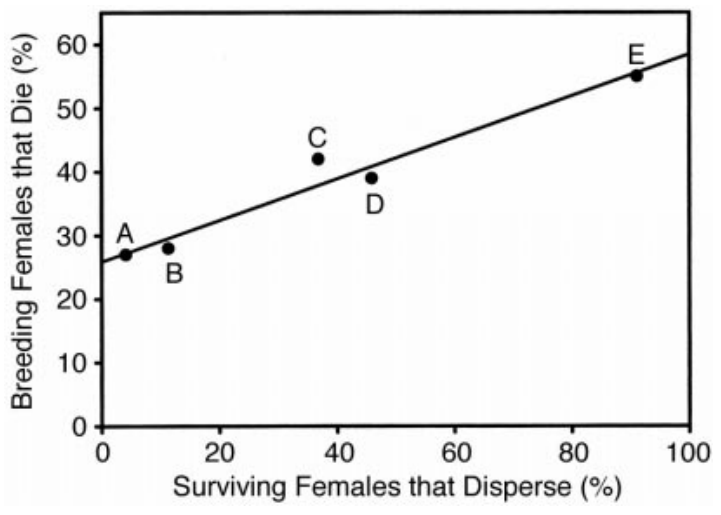

FIG. 6. Mortality cost of dispersal for breeding female Red-cockaded Woodpeckers, estimated by a plot of mortality rates (percentage of breeding females that died) against breeding dispersal rates (percentage of survivors that dispersed) for females in each of five exclusive circumstances: (A) no mate death or reproductive failure, $n=1327$; (B) reproductive failure, $n=501$; (C) mate death and reproductive failure, $n$ = 159; (D) mate death, $n=321$; (E) son inherits, $n=108$. Mortality of females that did not disperse is estimated to be $26 \%$ (left $y$-intercept). Mortality for females that dispersed is estimated to be $59 \%$ (right $y$-intercept). The difference between these rates is the estimated cost of breeding dispersal: an additional $33 \%$ mortality for dispersing females, more than double the "background" mortality rate for site-faithful females.

\section{Mate choice}

Improvement in mate quality (mate choice) is an important cause of breeding dispersal in many species of birds, including Black-capped Chickadees (Parus atricapillus; Otter and Ratcliffe 1996), Blue Tits (Parus caeruleus; Dhondt and Adriaensen 1994), and Large Cactus Finches (Geospiza conirostris; Grant and Grant 1987). Mate choice is usually illustrated by females switching to older males (Grant and Grant 1987, Dhondt and Adriaensen 1994), but sometimes by females switching to more dominant males (Otter and Ratcliffe 1996). In this study, mate choice was manifested by females moving to avoid young replacement males. Again, that behavior appears to be adaptive, as reproductive capability of young males is considerably less than that of older males.

There was no clear evidence that female Red-cockaded Woodpeckers disperse to improve male quality if their mates survive. Females dispersed more frequently after mating with young males, probably because young males experienced greater rates of nest failure. However, females dispersing while their mates survived did not acquire older mates. In addition, there was no evidence that low productivity of successful nests affected dispersal. If females dispersing after reproductive failure had remained on territory, chances of another failure would have been reduced as their mates aged. Therefore, associations among male age, reproductive failure, and dispersal of young females do not provide clear evidence for the mate choice hypothesis.

By definition, males that survive but are left by females are $\geq 2$ yr old, whereas no such constraint exists for replacement males. It may be that, in the set of males $\geq 2$ yr old, there is not enough variation in male quality to influence dispersal of breeding females. Alternatively, perhaps females disperse from surviving mates to improve male quality, but this quality is not reflected by male age. Finally, the chances of finding a male $>2$ yr old may not be high enough to promote breeding dispersal for this set of females.

Proximate mechanisms of judging male quality are unknown. In cases involving mate death, age of immigrant replacement males strongly affects the decision to move. Females may be able to discern the age of strange males by behavior or appearance, or instead may leave if no immediate replacement arrives, a sign that the incoming male may be a dispersing yearling, rather than a nearby, older helper. Indications of male quality other than age undoubtedly exist, but remain unknown even in this well-studied species.

Male quality is difficult to separate from territory quality with respect to both proximate mechanisms and ultimate significance. A female may judge a male by the quality of the site he defends rather than something intrinsic to the male himself; in this scenario, it is the male that provides higher fitness and the territory is an indicator of male quality. This may be equally possible in the reverse: a female may judge a territory by the quality of the male present, but the territory produces the fitness effect. Finally, there could well be site-male interactions, whereby a high-quality male and a highquality territory together provide the female with higher fitness than the contribution of each one separately.

\section{Site choice}

Relatively few studies of breeding dispersal have shown that birds disperse to obtain a better site, in part because of the difficulty in separating site and mate quality, but also because many studies of mate change have focused on mate effects rather than site effects (reviewed by Choudhury 1995). However, site choice clearly influences breeding dispersal in some species: Tengmalm's Owls (Aegolius funereus) move after depletion of site resources (Korpimäki 1993); female Indigo Buntings change sites more often after unsuccessful nests, regardless of the fate of their mates (Payne and Payne 1993); and Pied Flycatchers (Ficedula hypoleuca) move to higher quality nest boxes as they age (Montalvo and Potti 1992). Site choice may influence breeding dispersal of Prothonotary Warblers (Protonaria citrea), which occasionally move from low-quality dry sites to high-quality flooded sites both within and between breeding seasons (Petit and Petit 1996).

Nest failure and low reproduction from successful nests are important to breeding dispersal at both ulti- 
mate and proximate levels. Both could be indicators of low-quality territories and, as such, serve as proximate mechanisms, and both suggest that birds disperse to increase fitness, the ultimate cause of adaptive behavior. Nest failure and/or low reproduction from successful nests are associated with breeding dispersal in many species of birds, including Red-winged Blackbirds (Agelaius phoeniceus; Beletsky and Orians 1991), kittiwakes (Coulson and Thomas 1983), Great Tits (Parus major; Harvey et al. 1979, Linden 1991), Eastern Kingbirds (Tyrannus tyrannus; Murphy 1996), Pied Flycatchers (Montalvo and Potti 1992), Collared Flycatchers (Ficedula albicollis; Part and Gustafsson 1989), and Bobolinks (Dolichonyx oryzivorous; Gavin and Bollinger 1988). Nest failure prompts within-season breeding dispersal in Prairie Warblers (Dendroica discolor) and other passerines, probably illustrating predator avoidance (Jackson et al. 1989). Nest failure and/or low reproduction from successful nests is not associated with breeding dispersal in Blue Tits (Dhondt and Adriaensen 1994) or Willow Tits (Parus montanus; Orell et al. 1994).

Evidence for site choice as a cause of the dispersal in this study is limited to reduced dispersal in the presence of helpers, which are known to enhance reproduction (Walters 1990), and increased dispersal of young females in response to reproductive failure. Reproductive failure may be influenced by site quality: rates of predation or kleptoparasitism of nest cavities (Kappes 1997), both potential sources of nest failure (LaBranche and Walters 1994), may change with habitat condition (Kappes and Harris 1995; F. C. James, personal communication). In addition, high annual variability in the number of groups not nesting suggests that the environment has some influence on that behavior. However, if reproductive failure is related to low site quality, the fact that young breeders experience more failures must be explained. Rates of predation and kleptoparasitism may increase for young breeders if nest defense is a skill acquired with age, and failure to attempt to nest may increase for young breeders through an interaction between environmental effects and breeder age.

Other predictions of the site choice hypothesis were not upheld, and we found no evidence that dispersal served to improve territory quality as measured by our index (annual production of fledglings divided by annual adult mortality). It may be that our index is faulty, as it assumes that territory quality is stable over many years. Yet, a similar index based on a shorter time would not separate male quality from site quality effects on reproduction, and would include greater sampling error in estimated mortality. For this species, an estimate of territory quality possibly distinct from male quality may be the number of good cavities that each territory contains (Davenport 1994). Nevertheless, a likely possibility is that site quality does not influence breeding dispersal of female Red-cockaded Wood- peckers, and that evidence consistent with the site choice hypothesis is better explained by other factors such as mate choice and pair bond formation by young females.

\section{Social constraints}

Breeding dispersal caused by social constraints has rarely been shown in birds, perhaps because the hypothesis is missing from the conceptual framework used by the many researchers of mate change (reviewed by Choudhury 1995). It is implicitly shown in an experimental study of mate change in Black-capped Chickadees (Otter and Ratcliffe 1996), in which 13 females with high-quality mates were removed from the population. Dispersing females filling those vacancies consistently acquired mates of higher quality than their previous mates; thus, mate choice was supported. Upon reintroduction, removed females displaced new females in all cases but one, evidence that femalefemale competition can prompt breeding dispersal. Whether social constraints influence dispersal in unmanipulated chickadee populations is unknown. Social constraints affect dispersal of breeding male Indigo Buntings (Payne and Payne 1993): older, presumably dominant males are much less likely to disperse than young males.

Evidence indicates that social constraints (femalefemale competition, within-group competition, and reproductive competition between mothers and sons) do not cause dispersal of adult female Red-cockaded Woodpeckers. Evidently, the effect on dispersal of reproductive competition between mothers and sons manifested upon the death of a breeding male does not extend to groups in which all members survive, contrary to the suggestion of Gowaty and Lennartz (1985).

Aggressive female-female interactions are observed every breeding season in this population of Red-cockaded Woodpeckers, and it has long been assumed that resident breeding females are at times displaced by immigrant females. In light of results presented here, we give several interpretations of those aggressive interactions: (1) females are not contesting the breeding position but, rather, group affiliation for the immigrant female; (2) immigrant females are testing to see if there is a breeding female present; (3) resident females win; or (4) dominant birds displace resident females but dominance is not related to age.

\section{Age of breeding females}

Young female Red-cockaded Woodpeckers are more likely to disperse than older birds, in large part because of the associations among reproductive failure, female age, and breeding dispersal. The behavioral and/or physiological reasons that inexperienced females are more likely to suffer nest failure and are less likely to attempt to nest than older females are unknown. A similar interaction of reproductive failure and female age on dispersal has been documented by Part and Gus- 
tafsson (1989), who proposed that amount and quality of prior local experience inversely affect both frequency of dispersal and dispersal distance. Prior local experience may be an important factor for female Redcockaded Woodpeckers. Alternatively, reproductive failure followed by dispersal of young females may represent aborted pair-bonding attempts.

\section{Estimated cost of breeding dispersal}

Mortality rates of breeding females increase under certain circumstances, just as dispersal rates increase under these same circumstances. Most notably, mortality and dispersal rates reach $55 \%$ and $41 \%$, respectively, for those breeding females whose sons inherit breeding status on their territories. Dispersal under that circumstance appears to be both obligatory and costly.

Estimated mortality cost of breeding dispersal (33\% additional mortality) is quite high. A breeding female has an estimated $26 \%$ risk of mortality while remaining on territory; the risk of mortality increases to an estimated 59\% should she attempt to disperse. Therefore, the female doubles her likelihood of dying by attempting to disperse. Although dispersal and mortality rates covaried with circumstance, annual variation in those rates was not correlated. We therefore suggest that breeding dispersal is not a response to available vacancies, but rather to events occurring on the original territory that are independent of breeding female mortality. Few events will provide a sufficient benefit of dispersal to outweigh its high cost, and we identified only two: avoiding inbreeding depression and avoiding being unpaired or paired with a young male. The high cost of breeding dispersal compared to potential benefits may explain why social constraints did not induce movement.

\section{Further research}

Of the movements of breeding females recorded in our study, $17 \%$ were by females that had not experienced loss of their mates or reproductive failure. Those movements could not be attributed to any hypothesis we tested. There may well be an additional, important factor affecting breeding dispersal in our study population. Interspecific interaction is a likely candidate, especially kleptoparasitism of cavities (Kappes 1997). F. C. James (personal communication) reported dispersal of breeding females in direct response to cavity usurpation by Red-bellied Woodpeckers (Melanerpes carolinus). Effects of Red-bellied Woodpeckers vary with habitat condition (F. C. James, personal communication) and availability of large snags (Kappes and Harris 1995). Southern flying squirrels (Glaucomys volans) are known to occupy cavities also in use by Redcockaded Woodpeckers, but that interaction does not appear to have negative effects on woodpeckers (Rudolph et al. 1990, Conner et al. 1996). Damage to cavities by Pileated Woodpeckers (Dryocopus pileatus) can cause abandonment of territories by both breeders
(Walters 1991); effects of such cavity damage were minimized in the study population by the installation of restrictors on enlarged cavities (Carter et al. 1989), but movement of females soon after enlargement may have occurred.

Further research, even for this well-studied species, is also necessary to determine (1) causes of reproductive failure and their interaction with breeder age; (2) proximate means of avoiding young and related mates; (3) a better estimate of site quality and its effects on breeding dispersal; and (4) whether dominance is based on traits other than age and, if so, how it influences breeding dispersal.

\section{ACKNOWLEDGMENTS}

We thank all of the graduate students, undergraduates, and field technicians who have participated in the collection of data from the Sandhills population, and P. D. Doerr and J. H. Carter III for their efforts in directing and managing the woodpecker project. Data were collected using funds provided by the Department of Defense, the Department of the Army, Fort Bragg, and by the National Science Foundation (BSR8307090, BSR-8717683). We also thank K. Smith, R. B. Payne, and an anonymous reviewer for insightful comments on an earlier draft.

\section{Literature Cited}

Beletsky, L. D., and G. H. Orians. 1991. Effects of breeding experience and familiarity on site fidelity in female Redwinged Blackbirds. Ecology 72:787-796.

Carter, J. H., III, R. T. Stamps, and P. D. Doerr. 1983. Status of the Red-cockaded Woodpecker in the North Carolina Sandhills. Pages 24-29 in D. A. Wood, editor. Proceedings of Red-cockaded Woodpecker symposia II. Florida Game and Freshwater Fish Commission and U.S. Fish and Wildlife Service, Atlanta, Georgia, USA.

Carter, J. H., III, J. R. Walters, S. H. Everhart, and P. D. Doerr. 1989. Restrictors for Red-cockaded Woodpecker cavities. Wildlife Society Bulletin 17:68-72.

Chandler, C. R. 1995. Practical considerations in the use of simultaneous inference for multiple tests. Animal Behaviour 49:524-527.

Choudhury, S. 1995. Divorce in birds: a review of the hypotheses. Animal Behaviour 50:413-429.

Conner, R. N., D. C. Rudolph, D. Saenz, and R. R. Schaefer. 1996. Red-cockaded Woodpecker nesting success, forest structure, and southern flying squirrels in Texas. Wilson Bulletin 108:697-711.

Coulson, J. C., and C. S. Thomas. 1983. Mate choice in the kittiwake gull. Pages 361-376 in P. Bateson, editor. Mate choice. Cambridge University Press, Cambridge, UK.

Daniels, S. J., and J. R. Walters. 2000. Inbreeding depression and its effects on natal dispersal in Red-cockaded Woodpeckers. Condor 102, in press.

Davenport, D. E. 1994. A quantitative analyses of habitat quality for the Red-cockaded Woodpecker. Thesis. North Carolina State University, Raleigh, North Carolina, USA.

Dhondt, A. A., and F. Adriaensen. 1994. Causes and effects of divorce in the Blue Tit Parus caeruleus. Journal of Animal Ecology 63:979-987.

Gavin, T. A., and E. K. Bollinger. 1988. Reproductive correlates of breeding-site fidelity in Bobolinks (Dolichonyx oryzivorus). Ecology 69:96-103.

Gowaty, P. A., and M. R. Lennartz. 1985. Sex ratios of nestling and fledgling Red-cockaded Woodpeckers (Picoides borealis) favor males. American Naturalist 126:347-353.

Grant, B. R., and P. R. Grant. 1987. Mate choice in Darwin's 
finches. Biological Journal of the Linnean Society 32:247270.

Greenwood, P. J. 1980. Mating systems, philopatry, and dispersal in birds and mammals. Animal Behaviour 28:11401162.

Greenwood, P. J., and P. H. Harvey. 1982. The natal and breeding dispersal of birds. Annual Review of Ecology and Systematics 13:1-21.

Harvey, P. H., P. J. Greenwood, and C. M. Perrins. 1979. Breeding area fidelity of Great Tits (Parus major). Journal of Animal Ecology 48:305-313.

Hilborn, R., and M. Mangel. 1997. The ecological detective: confronting models with data. Princeton University Press, Princeton, New Jersey, USA.

Holm, S. 1979. A simple sequentially rejective multiple test procedure. Scandinavian Journal of Statistics 6:65-70.

Holmes, W. G., and P. W. Sherman. 1983. Kin recognition in animals. American Scientist 71:46-55.

Jackson, W. M., S. Rohwer, and V. Nolan Jr. 1989. Withinseason breeding dispersal in Prairie Warblers and other passerines. Condor 91:233-241.

Kappes, J. J., Jr. 1997. Defining cavity-associated interactions between Red-cockaded Woodpeckers and other cavity-dependent species: interspecific competition or cavity kleptoparasitism. Auk 114:778-780.

Kappes, J. J., Jr., and L. D. Harris. 1995. Interspecific competition for Red-cockaded Woodpecker cavities in the Apalachicola National Forest. Pages 389-393 in D. L. Kulhavy, R. G. Hooper, and R. Costa, editors. Red-cockaded woodpecker: recovery, ecology, and management. Center for Applied Studies in Forestry, Stephen F. Austin State University, Nacogdoches, Texas, USA.

Koenig, W. D., R. L. Mumme, and F. A. Pitelka. 1984. The breeding system of the Acorn Woodpecker in central coastal California. Zeitschrift für Tierpsychologie 65:289-308.

Korpimäki, E. 1993. Does nest-hole quality, poor breeding success or food depletion drive the breeding dispersal of Tengmalm's Owls? Journal of Animal Ecology 62:606613.

LaBranche, M. S., and J. R. Walters. 1994. Patterns of mortality in nests of Red-cockaded Woodpeckers in the Sandhills of southcentral North Carolina. Wilson Bulletin 106: 258-271.

Lennartz, M. R., R. G. Hooper, and R. F. Harlow. 1987. Sociality and cooperative breeding of Red-cockaded Woodpeckers (Picoides borealis). Behavioural Ecology and Sociobiology 20:77-88.

Ligon, J. D., and S. H. Ligon. 1990. Green Woodhoopoes: life history traits and sociality. Pages $33-65$ in P. B. Stacey and W. D. Koenig, editors. Cooperative breeding in birds: long-term studies of ecology and behavior. Cambridge University Press, Cambridge, UK.

Linden, M. 1991. Divorce in Great Tits-chance or choice? An experimental approach. American Naturalist 138:10391048.

Montalvo, S., and J. Potti. 1992. Breeding dispersal in Spanish Pied Flycatchers Ficedula hypoleuca. Ornis Scandinavica 23:491-498.

Murphy, M. T. 1996. Survivorship, breeding dispersal, and mate fidelity in Eastern Kingbirds. Condor 98:82-92.

Orell, M., S. Rytkonen, and K. Koivula. 1994. Causes of divorce in the monogamous Willow Tit, Parus montanus, and consequences for reproductive success. Animal Behaviour 48:1143-1154-.

Otter, K., and L. Ratcliffe. 1996. Female initiated divorce in a monogamous songbird: abandoning mates for males of higher quality. Proceedings of the Royal Society of London B 263:351-354.

Part, T., and L. Gustafsson. 1989. Breeding dispersal in the Collared Flycatcher (Ficedula albicollis): possible causes and reproductive consequences. Journal of Animal Ecology 58:305-320.

Payne, R. B., and L. L. Payne. 1993. Breeding dispersal in Indigo Buntings: circumstances and consequences for breeding success and population structure. Condor 95:124

Petit, L. J., and D. R. Petit. 1996. Factors governing habitat selection by Prothonotary Warblers: field tests of the Fretwell-Lucas models. Ecological Monographs 66:367-387.

Rice, W. R. 1989. Analyzing tables of statistical tests. Evolution 43:223-225.

Rudolph, D. C., R. N. Conner, and J. Turner. 1990. Competition for Red-cockaded Woodpecker roost and nest cavities: effects of resin age and entrance diameter. Wilson Bulletin 102:23-36.

Walters, J. R. 1990. Red-cockaded Woodpeckers: a "primitive" cooperative breeder. Pages 67-101 in P. B. Stacey and W. D. Koenig, editors. Cooperative breeding in birds: long-term studies of ecology and behavior. Cambridge University Press, Cambridge, UK.

Walters, J. R. 1991. Application of ecological principles to the management of endangered species. Annual Review of Ecology and Systematics 22:505-523.

Walters, J. R., P. D. Doerr, and J. H. Carter III. 1988. The cooperative breeding system of the Red-cockaded Woodpecker. Ethology 78:275-305.

Woolfenden, G. E., and J. W. Fitzpatrick. 1984. The Florida Scrub Jay. Princeton University Press, Princeton, New Jersey, USA. 